\title{
Dual-loop Control Strategy for Grid-connected Inverter with LCL Filter
}

\author{
Qiubo Peng, Hongbin Pan, Yong Liu, Lidan Xiang \\ Key Laboratory of Intelligent Computing \& Information Processing of Ministry of Education, \\ Xiangtan University, Xiangtan, China \\ Email: pengqiubo2008@qq.com \\ Received February, 2013
}

\begin{abstract}
As to the concrete topology of three-phase LCL type grid-connected inverter with damping resistance, mathematical model was deduced in detail, using method of equivalent transformation to the structure diagram, damping resistance was virtualized, mathematical model under the DQ frame that can realize decoupling control was established, a dual-loop control strategy for grid-connected inverter with LCL filter was proposed, the system stability was analyzed and the design method of controller was given. The proposed method overcame the flaws of loss increase, efficiency reduce and cost increase which were caused by damping resistance in LCL type grid-connected inverter, the system efficiency and power supply quality of the output were improved. Feasibility and effectiveness of the new method were validated by simulation and experimental results.
\end{abstract}

Keywords: Virtual Damping; LCL Filter; Three-phase Grid-connected Inverter; Decoupling Control

\section{Introduction}

LCL filter compared with the traditional L filter, it needs smaller inductance value and it is more effective for restraining higher harmonic when they achieve the same filtering effect, but resonance problem exists in LCL filter itself, it will cause system instability [1-3]. There are two common methods to solve it $[4,5]$ : one is passive damping, that is, a damping resistance is connected with the capacitor branch in series to inhibit resonance [6,7]. This method is simple and reliable, but the LCL filter's ability of restraining higher harmonic was reduced, it will also bring extra system loss for the damping resistor; another one is active damping, namely the modified control algorithm was adopted to inhibit resonance and make sure the system stability $[8,9]$.

According to the principle of inhibiting resonance by using damping resistance, and using equivalent transformation, a dual-loop control strategy for grid-connected inverter with LCL filter was proposed in this paper, this new method was used to inhibit resonance, ensure system stability. A detailed description about the process of proposing control strategy, mathematical modeling and decoupling control of grid-connected inverter in the DQ coordinate system, and the design method of controller parameter was given in this paper. Then system stability was analyzed, finally, the effectiveness and feasibility of the new method have been verified by simulate and ex- perimental ways.

\section{The Topology and Mathematical Model of Grid-connected Inverter with LCL Filter}

\subsection{The Mathematical Model of LCL Filter with Damping Resistance}

The topological structure of LCL grid-connected inverter with damping resistance is shown in Figure 1. Where, $L_{1}$ is inductance on the side of inverter, $R_{1}$ is parasitic resistance; $L_{2}$ is inductance on the side of grid, $R_{2}$ is parasitic resistance; $C$ is filter capacitor, $R_{c}$ is damping resistance connecting with $C$ in series; $V_{d c}$ is DC-bus voltage, $u_{a} u_{b} u_{c}$ are three-phase output voltages of inverter, $i_{1 a} i_{1 b} i_{1 c}, i_{2 a} i_{2 b} i_{2 c}$ and $i_{C a} i_{C b} i_{C c}$ are threephase currents on the side of inverter, three-phase currents on the side of grid and three-phase currents flowing

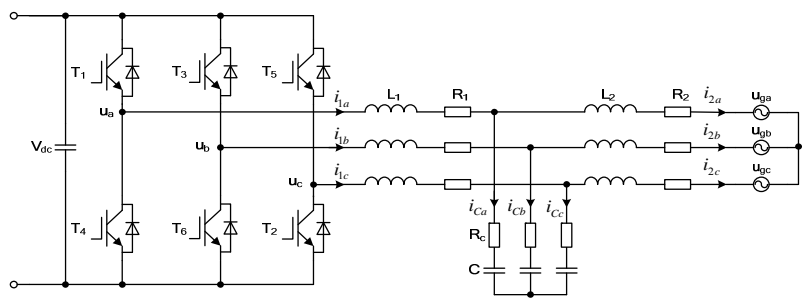

Figure 1. Grid-connected inverter with LCL filter based on damping resistance. 
through filter capacitor, respectively, $u_{g a} u_{g b} u_{g c}$ are three-phase grid voltages.

$i_{1 a} i_{1 b} i_{1 c}, i_{2 a} i_{2 b} i_{2 c}$ and voltages of filter capacitor $u_{C a} u_{C b} u_{C c}$ are selected as state variables to obtain state equation in the three phase static coordinate system. Transfer functions in the $\alpha \beta$ coordinate system were obtained by using Laplace transform and Clarke transform to the state equation, then, transfer functions in the DQ coordinate system were obtained by using Park transform to the frontal transfer functions, it is as follows:

$$
\begin{aligned}
& \left\{\begin{array}{l}
I_{1 d}=\frac{U_{d}-U_{C d}+w L_{1} I_{1 q}}{L_{1} s+R_{1}} \\
I_{2 d}=\frac{U_{C d}-U_{g d}+w L_{2} I_{2 q}}{L_{2} s+R_{2}} \\
I_{C d}=I_{1 d}-I_{2 d} \\
U_{C d}=\frac{\left(R_{C} C s+1\right) I_{C d}-w R_{C} C I_{C q}+w C U_{C q}}{C s}
\end{array}\right. \\
& \left\{\begin{array}{l}
I_{1 q}=\frac{U_{q}-U_{C q}-w L_{1} I_{1 d}}{L_{1} s+R_{1}} \\
I_{2 q}=\frac{U_{C q}-U_{g q}-w L_{2} I_{2 d}}{L_{2} s+R_{2}} \\
I_{C q}=I_{1 q}-I_{2 q} \\
U_{C q}=\frac{\left(R_{C} C s+1\right) I_{C q}+w R_{C} C I_{C d}-w C U_{C d}}{C s}
\end{array}\right.
\end{aligned}
$$

where, $I_{1 d}, I_{2 d}, I_{C d}, U_{C d}, U_{d}$ and $U_{g d}$ is D-axis current on the side of inverter, current on the side of grid, the output voltage of inverter and grid voltage, respectively. Similar tagging method to $\mathrm{D}$-axis variables is adopted for Q-axis variables.

The block diagram of LCL filter with damping resistance and blocking capacitance can be obtained from transfer functions in the DQ coordinate system, D-axis structure diagram is shown in Figure 2 as example:

\subsection{Equivalent Transformation of the System Block Diagram}

The equivalent transformation is as follows: 1) Moving signal comparing point of the feedback loop $I_{C q}$ to the left side of the signal comparing point of the feedback loop $U_{C d}$ by equivalent transformation and shown in Figure 3(a); 2) Doing equivalent transformation to

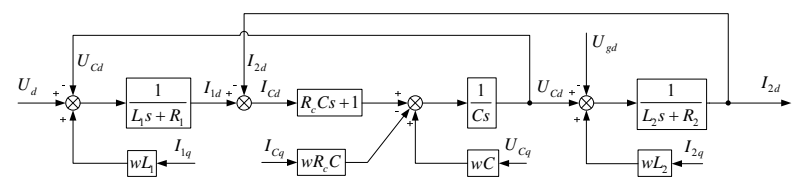

Figure 2. D-axis block diagram of LCL filter based on damping resistance.

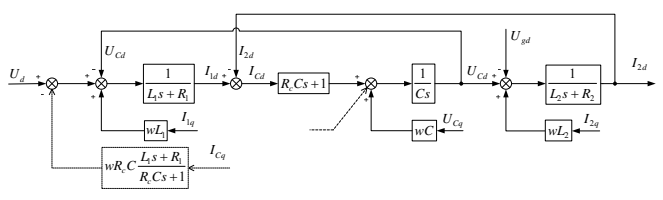

(a)

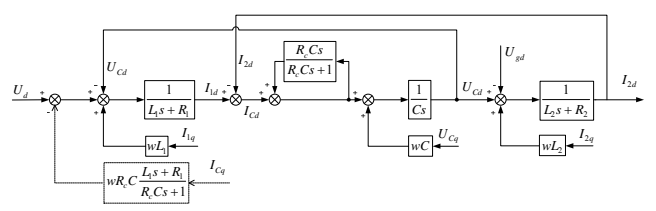

(b)

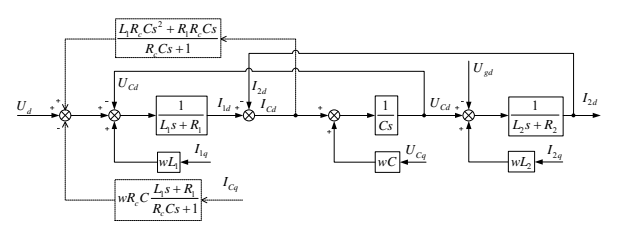

(c)

Figure 3. Equivalent transforms of LCL filter based on damping resistance.

" $R_{c} C s+1$ " as Figure 3(b); 3) Moving signal comparing point of the equivalent part of "(2)"to the left side of the signal comparing point of the feedback loop $U_{C d}$ by equivalent transformation, finally, the equivalent block diagram is obtained and shown in Figure 3(c).

Equivalent transforms in the above paragraphs was called "virtualization process of damping resistance", whereas the dotted portions in the figure can be called "virtual damping resistance". The remaining solid portions are the block diagram of LCL filter without damping resistance. The conclusion that it needs capacitance current and grid-connected current double closed loop control in order to achieve the same filtering effect as before the equivalent transforms is obtained from the transform results.

\section{Current Dual-loop Control Strategy}

\subsection{Control Strategy}

The output current of three-phase grid-connected inverter with LCL filter will have higher quality, but it demands higher requirement of control. The system is unstable if using typical grid-connected current direct feedback closed loop control. Conclusion that is obtained from the block diagram in the above paragraphs is that: it can achieve the same effect of inhibiting resonance as using a damping resistance in the filter capacitor branch in series by adopting the filter capacitor current feedback as well as proper control strategy.

If "virtual damping resistance" that is from the equivalent transformation is directly used in controlling, due to the order of its transfer function numerator is higher than 
that of the denominator, feedback quantity is the filter capacitor current, the current harmonic is high and the control is more difficult, it is difficult to achieve the effect of inhibiting resonance and system stability and this is verified by simulation result.

Now that the control effect is not good by using "virtual damping resistance" directly that is from the equivalent transformation, only the feedback quantity is taken in the control that is simplified in this paper. Current double closed loop control strategy is used in three-phase grid-connected inverter with LCL filter and the feedback quantity is the filter capacitor current $I_{C}$ and the gridconnected current $I_{2}$ on the grid side. A P control is applied in the filter capacitor current inner loop and a PI control is applied in the grid-connected current outer loop.

\subsection{System Performance Analysis and Controller Parameter Design}

Current double closed loop control for grid-connected inverter consists of capacitor current inner loop and gridconnected current outer loop. Voltage-current double closed loop control for grid-connected inverter consists of grid-connected current inner loop and grid voltage outer loop. Because the control principle is different between the two, it cannot adopt a similar method to the latter to design current double closed loop controller in this paper [10]. The setting value of the current double closed loop control in this paper is current instruction, the reference current of the capacitor current inner loop will be obtained after flowing through outer PI controller, then, the voltage instruction will be obtained after flowing through inner $\mathrm{P}$ controller and it will be sent to inverter. The inner or outer loop cannot be designed independently because of the interdependence between the two, only the inner and outer loop controllers were designed synchronously in order to ensure system performance.

Due to the duality between D-axis and Q-axis, only taking D-axis controller design for example in what follows. The system control block diagram is shown in Figure 4.

Where, Inverter Bridge is equivalent to proportional component $K_{p w m}, K_{1}$ is the feedback coefficient of capacitor current inner loop and $K_{2}$ is the feedback coefficient of grid-connected current outer loop.

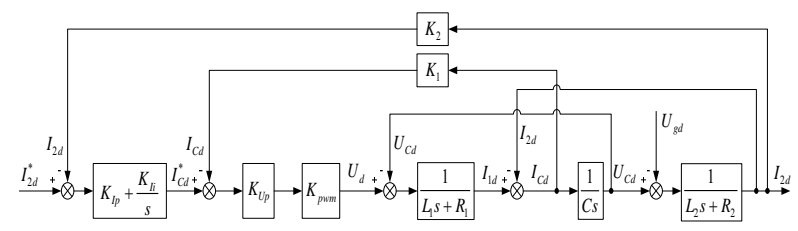

Figure 4. Control block diagram of D-axis.
According to the control block diagram and ignoring the parasitic resistance $R_{1}$ and $R_{2}$ of the inductance, the open loop transfer function of the system can be obtained as follows:

$$
G(s)=\frac{K_{2} K_{U p} K_{I p} K_{p w m} s+K_{2} K_{U p} K_{I i} K_{p w m}}{s^{2}\left[L_{1} L_{2} C s^{2}+K_{1} K_{U p} K_{p w m} L_{2} C s+\left(L_{1}+L_{2}\right)\right]}
$$

The closed loop transfer function is:

$$
\Phi(s)=\frac{b_{1} s+b_{0}}{a_{4} s^{4}+a_{3} s^{3}+a_{2} s^{2}+a_{1} s+a_{0}}
$$

where,

$$
\begin{gathered}
a_{4}=L_{1} L_{2} C, a_{3}=K_{1} K_{U p} K_{p w m} L_{2} C, a_{2}=L_{1}+L_{2}, \\
a_{1}=K_{2} K_{U p} K_{I p} K_{p w m}, a_{0}=K_{2} K_{U p} K_{I i} K_{p w m}, \\
b_{1}=K_{U p} K_{I p} K_{p w m}, \quad b_{0}=K_{U p} K_{I i} K_{p w m} .
\end{gathered}
$$

The system stability condition can be obtained as follows by using Routh stability criterion.

$$
\left\{\begin{array}{l}
K_{1}\left(L_{1}+L_{2}\right)-K_{2} K_{I p} L_{1}>0 \\
K_{1} K_{I p}\left(L_{1}+L_{2}\right)-K_{2} K_{I p}^{2} L_{1}-K_{1}^{2} K_{U p} K_{I i} K_{p w m} L_{2} C>0
\end{array}\right.
$$

Therefore, it can ensure the system stability as long as satisfying the above identities when designing controller.

From the open loop transfer function of the system, it can be seen that this system is a II type system and contains a second-order system. Let be the open loop transfer function $G(s)=\frac{K\left(T_{1} s+1\right)}{s^{2}\left(T_{2}^{2} s^{2}+2 \zeta T_{2} s+1\right)}$, where

$$
K=\frac{K_{2} K_{U p} K_{I i} K_{p w m}}{L_{1}+L_{2}}, T_{1}=\frac{K_{I p}}{K_{I i}}, T_{2}^{2}=\frac{L_{1} L_{2} C}{L_{1}+L_{2}},
$$

$2 \zeta T_{2}=\frac{K_{1} K_{U p} K_{p w m} L_{2} C}{L_{1}+L_{2}}, \zeta$ is damping coefficient.

Using the design method of controller based on expected logarithmic frequency characteristic in what follows: They can be calculated from the open loop transfer function: $T_{2}=\frac{1}{w_{2}}=\sqrt{\frac{L_{1} L_{2} C}{L_{1}+L_{2}}}, \quad K_{U p}=\frac{2 \zeta T_{2}\left(L_{1}+L_{2}\right)}{K_{1} K_{p w m} L_{2} C}$, also $h=\frac{w_{2}}{w_{1}}=\frac{T_{1}}{T_{2}}$, selecting middle-frequency width coefficient $h, T_{1}=\frac{1}{w_{1}}=h T_{2}$ can be calculated; selecting a suitable $K$ that satisfies $\frac{1}{T_{1}}<\sqrt{K}<\frac{1}{T_{2}}$, $K_{I i}=\frac{K\left(L_{1}+L_{2}\right)}{K_{2} K_{U p} K_{p w m}} \quad$ can be calculated; finally, $K_{I p}=T_{1} K_{I i}$ can be calculated.

By substituting system parameters $L_{1}=1.6 \mathrm{mH}$, 
$L_{2}=1 \mathrm{mH}, C=20 u F$, selecting optimal damping coefficient in engineering $\zeta=0.707$, feedback coefficient of

the current loops $K_{1}=K_{2}=\frac{1}{2200 \sqrt{2}}$, equivalent proportional coefficient of the Inverter Bridge $K_{p w m}=300$, middle-frequency width coefficient $h=10$, three controller parameters $K_{U p}, K_{I p}$ and $K_{I i}$ can be obtained. A group of controller parameters can be obtained when selecting a $K$. For example, when $K=2.25 \times 10^{6}$, $K_{U p}=211.494, K_{I p}=0.318$ and $K_{I i}=286.863$ can be obtained. When selecting $\sqrt{K}=1 w_{1}, \sqrt{K}=1.25 w_{1}$, $\sqrt{K}=1.5 w_{1}, \sqrt{K}=1.75 w_{1}$ and $\sqrt{K}=2 w_{1}$, respectively, amplitude margins of the system range from $7.84 \mathrm{~dB}$ to $19.88 \mathrm{~dB}$ and phase margins range from $36^{\circ}$ to $42^{\circ}$. All performance indexes of the system are good, and it satisfies the system stability condition that is obtained from the Routh criterion in the above paragraphs. All of them have proved feasibility of the design in the above paragraphs. Frequency characteristic of the system are plotted under 5 groups of parameters in the above paragraphs. They are characteristic curves of increasing $K$ from up to down in the figure and shown in Figure 5.

\section{Simulation Analysis}

In order to verify correctness of the theoretical analysis in the above paragraphs, a simulation model was built in Matlab/Simulink. Using the control strategy in this paper and SVPWM (space vector pulse width modulation) strategy, controlling in DQ coordinate system by using $3 / 2$ transform and $2 \mathrm{~s} / 2 \mathrm{r}$ transform, and the phase and frequency of grid are locked by three phase phase-locked loop (PLL). The power of grid-connected inverter is $36 \mathrm{kVA}$ in simulation, grid voltage is $380 \mathrm{~V} / 50 \mathrm{~Hz}$, DCbus voltage is $700 \mathrm{~V}$ and the maximum grid-connected peak current is 77A. Switching frequency is $10 \mathrm{kHz}$, a group of parameters $K_{U p}=211.494, K_{I p}=0.318$ and $K_{I i}=286.863$ that are obtained in the above paragraphs are adopted as the controller parameters and the remaining system parameters are the same as them in the above paragraphs. All voltages and currents are treated with per unit in the simulation in order to calculate and control simply.

All the waveforms in the following paragraphs take A phase waveform in the three phase as example. Figure 6 is the simulation waveforms of three phase LCL type grid-connected inverter with damping resistance. When the reference current is 0.25 p.u., the fundamental amplitude of grid-connected current is 0.2501 p.u., DC component is $4.039 \times 10-5$ p.u. and the THD (total harmonic distortion) is $0.67 \%$.

When using dual-loop control strategy for grid-connected inverter with LCL filter, simulation result is shown in Figure 7. When the reference current is 0.25 p.u., the fundamental amplitude of grid-connected current is 0.2502 p.u., DC component is $6.129 \times 10^{-6}$ p.u. and the THD is $0.55 \%$.

When the load changes from half load to full load and full load to half load, grid-connected inverter dynamic response waveforms are shown in Figure 8. It is can be known that the system still can run stably and has good dynamic performance when grid-connected current changing from the waveforms.
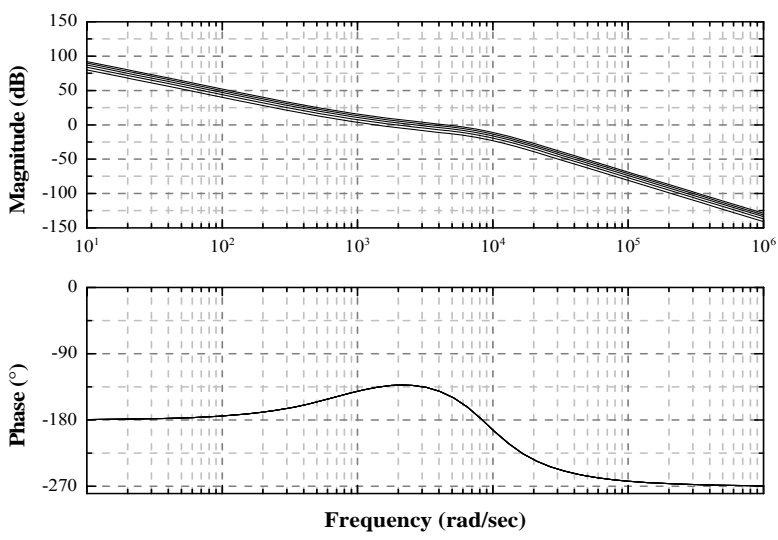

Figure 5. Bode plot of system.
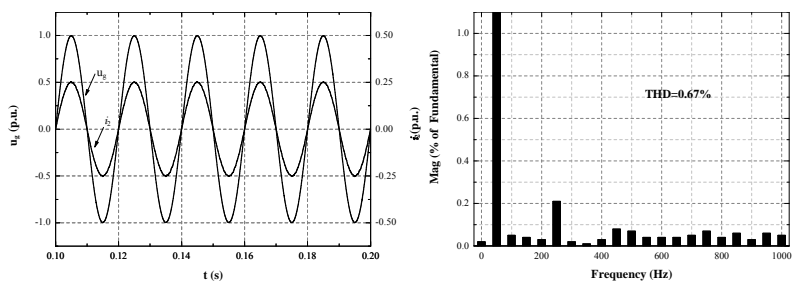

Figure 6. Simulation waves and harmonic analysis based on damping resistance.

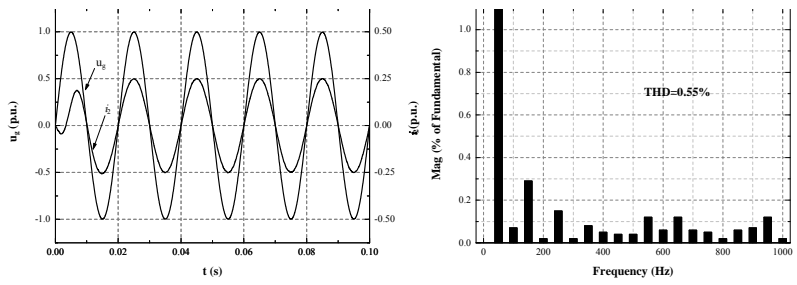

Figure 7. Simulation waves and harmonic analysis based on dual-loop control.

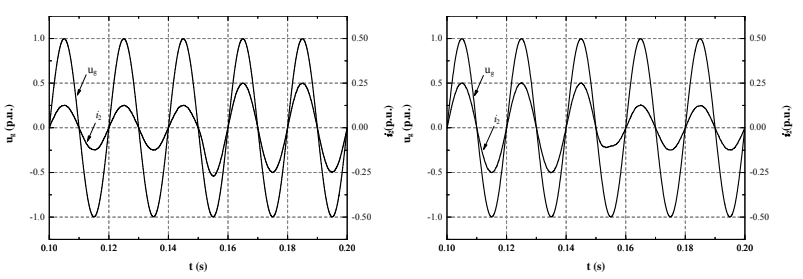

Figure 8. Simulation waves of load changing, half-full(left), full-half(right). 


\section{Experimental Results}

An experimental prototype for $3 \mathrm{kVA}$ output power has been successfully implemented based on the theoretical analysis and simulation experiments in the above paragraphs by using TM320F2812 DSP as the digital controller. Figure 9 is the experimental waveforms of three phase LCL type grid-connected inverter with damping resistance. In this case, grid-connected current is $4.54 \mathrm{~A}$ and THD is $3.54 \%$. When using dual-loop control strategy for grid-connected inverter with LCL filter, experimental result is shown in Figure 10. By this method, grid-connected current is $4.52 \mathrm{~A}$ and THD is $3.68 \%$. It can be obtained from the experimental results. When using the new control strategy, it can achieve the same inhibiting resonance as the method of using real damping resistance. At the same time, good power supply quality of the output can be ensured.

\section{Conclusions}

The dual-loop control strategy for grid-connected inverter with LCL filter in this paper can be used to control the currents of three phase grid-connected inverter, and it will let grid-connected inverter has a stronger ability of harmonic suppression. A detailed description about theoretical basis of the control strategy and design method of the controller were given in this paper, the effectiveness of the new control strategy has been verified by simulation and prototype experiment.

Compare with the control method of inhibiting resonance by using damping resistance, the new control method in this paper has characters as follows: a) good

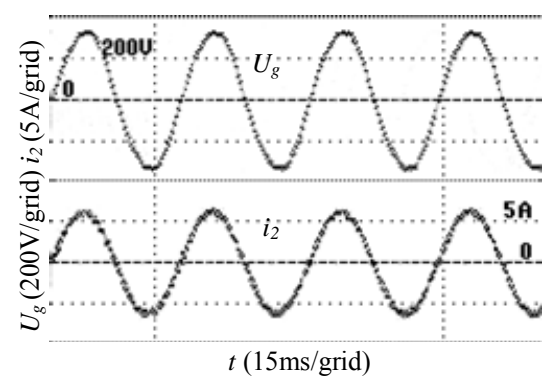

Figure 9. Experimental waves based on damping resistance.

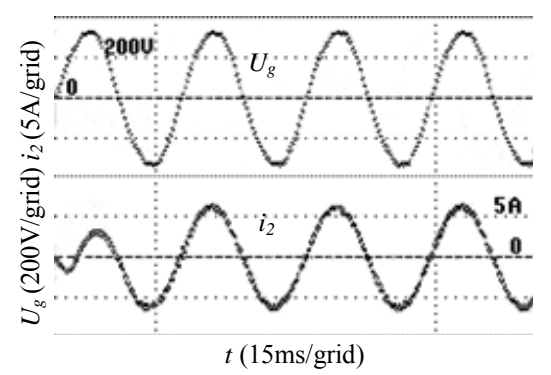

Figure 10. Experimental waves based on dual-loop control. power supply quality of the output: low harmonics, especially has a stronger ability of high harmonic suppression, and has solved the system unstable problem caused by resonance; b) system sufficiency was improved further: the real damping resistance has been canceled, it has no extra loss caused by real damping resistance.

\section{Acknowledgements}

This work is supported by the Key Laboratory of Intelligent Computing \& Information Processing (Xiangtan University), Ministry of Education and the construct program of the key discipline in hunan province.

\section{REFERENCES}

[1] Y. Q. Wang, F. J. Wu, L. Sun, et al., "Optimized Design of LCL Filter for Minimal Damping Power Loss," Proceedings of the CSEE, Vol. 30, No. 27, 2010, pp. 90-95.

[2] M. Liserre, A. Dell'Aquila and F. Blaabjerg, "Stability Improvements of an LCL-filter Based Three-phase Active Rectifier," IEEE Annual Power Electronics Specialists Conference, Cairns, 2002.

[3] X. H. Wang, X. B. Ruan and S. W. Liu, "Control Strategy for Grid-connected Inverter to Suppress Current Distortion Effected by Background Harmonics in Grid Voltage," Proceedings of the CSEE, Vol. 31, No. 6, 2011, pp. 7-14.

[4] C. H. Zhang, Y. Ye, A. Chen, et al., "Research on Grid-connected Photovoltaic Inverter Based on Output Current Control," Transactions of China Electrotechnical Society, Vol. 22, No. 8, 2007, pp. 41-45.

[5] T. C. Y. Wang, Z. H .Ye, G. Sinha, et al., "Output Filter Design for a Grid-interconnected Three-phase Inverter," IEEE PESC'03, Acapulco, Mexico, 2003.

[6] Z. Y. Xu, A. G. Xu and S. J. Xie, "Dual-loop Grid Current Control Technique for Grid-connected Inverter Using an LCL Filter," Proceedings of the CSEE, Vol. 29, No. 27, 2009, pp. 36-41.

[7] M. Malinowski and S. Bernet, "A Simple Voltage Sensorless Active Damping Scheme for Three-phase PWM Converters with an LCL Filter," IEEE Transactions on Industry Electronics, Vol. 55, No. 4, 2008, pp. 1876-1880.

[8] Ji Bao-jian, F. Hong and J. F. Zhao, "A Non-isolated Three-level Dual Buck Photovoltaic Grid-connected Inverter," Proceedings of the CSEE, Vol. 32, No. 12, 2007, pp. 7-13.

[9] B. C. Wang, X. Q. Guo, Q. Mei, et al., "DC Injection Control for Transformerless PV Grid- connected Inverters," Proceedings of the CSEE, Vol. 29, No. 36, 2009, pp. 23-28.

[10] F. Liu, S. X. Duan and X. M. Zha, "Design of Two Loop Controller in Grid-connected Inverter with LCL Filter," Proceedings of the CSEE, Vol. 29, No. S1, 2009, pp. 234-240. 